\title{
Os processos de aprendizagem e o Transtorno do Espectro do Autismo (TEA): a trajetória de um aluno do segundo ao terceiro ano do Ensino Fundamental
}

\begin{abstract}
Resumo:
O presente texto tem como objetivo apresentar um relato de experiência construído durante uma bolsa de monitoria em Educação Especial no Colégio de Aplicação da UFRGS, contemplando os avanços no processo de aprendizagem de um aluno com Transtorno do Espectro do Autismo (TEA) em toda a sua trajetória do segundo ao terceiro ano do Ensino Fundamental, principalmente em seu processo de escrita e fala. Para isso, analisam-se as práticas pedagógicas utilizadas em sala de aula, a rotina escolar e o cotidiano do aluno a fim de buscar ferramentas facilitadoras para a construção do conhecimento, a consolidação da autonomia e a socialização. As considerações decorrentes das análises apontam para a importância da transversalidade da educação especial no contexto escolar, de um currículo flexível e abrangente e da formação de professores voltada para a prática da educação na perspectiva inclusiva; destacando também as possibilidades que o ensino, a pesquisa e a extensão trazem para o ensino público, colocando em execução as políticas de inclusão social.
\end{abstract}

\section{Palavras-chave:}

Autismo. Aprendizagem. Autonomia. Escolarização.

\begin{abstract}
:
The present text aims to present an experience report built during a special education monitoring scholarship at the UFRGS Application College, contemplating the advances in the learning process of a student with Autism Spectrum Disorder (ASD) throughout his life. trajectory from the second to the third year of elementary school, mainly in its writing and speaking process. For this, the pedagogical practices used in the classroom, the school routine and the student's daily life are analyzed in order to seek tools that facilitate the construction of knowledge, the consolidation of autonomy and socialization. The considerations arising from the analyzes point to the importance of the transversality of special education in the school context, of a flexible and comprehensive curriculum and of teacher training focused on the practice of education in an inclusive perspective; also highlighting the possibilities that teaching, research and extension bring to public education, implementing social inclusion policies.
\end{abstract}

\section{Keywords:}

Autism. Learning. Autonomy. Schooling.

\footnotetext{
* Estudante de licenciatura na Universidade Federal do Rio Grande do Sul e monitora de inclusão no Colégio de Aplicação da UFRGS. E-mail: bruna.barros.borba@gmail.com. ORCID iD: http://orcid.org/0000-0003-2966-2748.
} 


\section{A educação especial}

Segundo a Lei no 15.322 , de 25 de setembro de 2019 art. $1^{\circ}$ visando ao desenvolvimento pessoal, à inclusão social e à cidadania e ao apoio às suas famílias, institui-se a Política Estadual de Atendimento Integrado à Pessoa com TEA buscando garantir o atendimento necessário às pessoas com Transtornos do Espectro Autista no Estado do Rio Grande do Sul. A política sempre foi uma ferramenta necessária para assegurar direitos e buscar uma sociedade mais justa e inclusiva, para a educação especial é de suma importância que a política e o fazer pedagógico andem juntos.

A terminologia TEA (Transtorno do Espectro Autista) foi formulada recentemente após muitos anos de pesquisa na área da educação especial, muitos autores dedicaram seus trabalhos para conceituar e caracterizar esse termo.

O transtorno do espectro autista caracteriza-se por déficits persistentes na comunicação social e na interação social em múltiplos contextos, incluindo déficits na reciprocidade social, em comportamentos não verbais de comunicação usados para interação social e em habilidades para desenvolver, manter e compreender relacionamentos. (AMERICAN PSYCHIATRIC ASSOCIATION, 2014, p. 75).

Como também, para além dos termos médicos, entendemos o autismo como um fator externo ao indivíduo, de responsabilidade social e dever do Estado; o conceito de deficiência criado a partir do social e instituído pela Política Nacional de Educação Especial na Perspectiva da Educação Inclusiva (PNEEPEI) foi formulado em 2008 e traz a deficiência para uma questão de vida e sociedade, colocando a educação inclusiva como centralidade no debate de uma sociedade contemporânea e a escola como responsável pela superação da lógica da exclusão.

Portanto, as diferenças precisam ser encaradas como fonte de recursos às transformações, ao invés de serem vistas como obstáculos. Trata-se de questionar o elo das relações humanas: a participação de cada sujeito, suas vivências e a estruturação das relações sociais. (SILVA et al., 2005, p. 2).

Quando em contato com a escolarização, o processo de aprendizagem de um aluno com TEA varia significativamente de acordo com as suas características e principalmente sua personalidade (levando em consideração que qualquer sujeito é influenciado pelo seu meio) e é a partir das práticas em sala de aula e da observação que o professor consegue utilizar de recursos para articular uma intervenção pedagógica em cada caso. Neste relato de experiência partiremos do princípio que o aluno já esteve em contato com a escolarização e, portanto, possui uma bagagem pedagógica que adquiriu durante todo o seu primeiro ano do Ensino Fundamental, já consolidou algumas aprendizagens e sua socialização apresenta maiores avanços com relação a seu primeiro contato com o ambiente escolar.

[...] pode-se entender por aprendizagem a maneira como cada um vive no dia a dia, um jeito de olhar para o mundo com atenção ao novo, ao diferente. Ou mesmo de se espantar com o que sempre esteve aí, como o brilho dos dias, o canto dos pássaros, a brincadeira das crianças. (ALVES, 2008, p. 98).

\section{A construção da segunda etapa dos anos iniciais}

A partir do compartilhamento entre professor titular de sala de aula e professor especializado do AEE (Atendimento Educacional Especializado aplicado como suplementação e/ou complementação do ensino regular) foram formulados objetivos esperados que o aluno alcançasse durante o ano letivo como consolidar o alfabeto e desenvolver a motricidade fina; tomando-os como base, as atividades a serem realizadas 
em aula juntamente com as avaliações de rendimento do aluno puderam ser projetadas de acordo com as respectivas demandas pedagógicas. Durante o segundo ano, um dos principais objetivos estava voltado à alfabetização e o conhecimento das palavras simples que o rodeavam em seu dia a dia: o próprio nome, a palavra mãe, pai, etc.

[...] a educação inclusiva requer que os professores criem e mantenham salas de aulas flexíveis. A instrução é voltada para alunos de todos os diferentes níveis de aproveitamento. [...] a instrução diferenciada [...]. Ela pede para que os professores criem salas de aula que se adequem às necessidades dos alunos, em vez de criar estudantes que se adequem às necessidades da sala de aula. (VALLE; CONNOR, 2014, p. 113).

Os avanços observados do início ao final do ano letivo foram significantes para caracterizar o processo de aprendizagem do estudante: sua comunicação era constituída muitas vezes por uma única palavra que expressasse suas vontades (água, xixi, etc.) e então, a partir disso essas palavras puderam ser incrementadas nas atividades com o alfabeto móvel para conhecimento das letras que a constituíam. A escrita simbólica era dominante, de forma que para cada letra da palavra haveria um símbolo respectivamente: já existia um significado concreto de palavra em sua aprendizagem, porém a representação gráfica ainda não estava presente; este aspecto foi muito importante para avaliar o avanço na modalidade de leitura e escrita, o aluno desde cedo demonstrou interesse pelos livros, já apresentava conhecimento da configuração de leitura (folhear o livro da direita para a esquerda) e acompanhava as histórias - do seu modo - pelas figuras, o que representou então uma ação de observação focada na estrutura dos textos.

O ensino da matemática se deu de forma lúdica com materiais concretos e sempre utilizando-se de recursos que já rodeavam a rotina do aluno, como contagem dos lápis de cores, brinquedos, números feitos de madeira, entre outros; sempre priorizando o material em relevo, que pode ser tocado e que salienta a forma do número para trabalhar também paralelamente com a escrita gráfica, articulando entre esses materiais e o contato que o estudante já possuía com vídeos e desenhos educativos infantis diariamente, ao final do segundo ano do Ensino Fundamental a contagem progressiva já alcançava o número 20.

A fala sempre foi um fator em desenvolvimento no processo de aprendizagem do aluno, as atividades de rotina na escola eram explicadas constantemente por professores e monitores a fim de estabelecer um diálogo e incentivar o repertório de frases e palavras que facilitassem a comunicação no cotidiano, o ato de expressar um sentimento ou uma vontade muitas vezes se tornava um processo difícil por persistir uma fala pouco compreensível. O brincar simbólico começou a aparecer durante o segundo ano e a partir de intervenções pedagógicas que estimulam o diálogo puderam ser notados avanços mais visíveis no decorrer do ano seguinte, uma delas foi a introdução do brincar de boneca para dentro da sala de aula: a boneca foi uma ferramenta potente não somente no processo de fala como também, na aprendizagem de atividades cotidianas como a higienização: no ato de brincar de boneca reproduzimos ações que fazem parte do dia a dia como utilizar o banheiro corretamente, trocar de roupa, tomar banho, etc. e através desse brincar muitas questões puderam ser trabalhadas na escola de forma leve e divertida "É essa reciprocidade que o trabalho pedagógico procura todo o tempo; tentar de várias formas que o sujeito consiga perceber o outro, ou outros que convivem com ele na família, na escola e na sociedade" (SILVA; BINS, 2016, p. 24).

\section{Resultados e observações na terceira etapa dos anos iniciais}

O trabalho realizado em conjunto com professor, educação especial e professor monitor (aluno de licenciatura na UFRGS selecionado por edital e entrevista para atuar como monitor de inclusão dando apoio e suporte nas atividades realizadas em aula) no ano antecedente se fez fundamental para estabelecer o ano seguinte, entretanto ao iniciar as aulas pode-se observar algumas regressões tanto na aprendizagem quanto no comportamento do estudante, o que mobilizou novamente a equipe de professores para formular 
objetivos mais urgentes e que pudessem também promover avanços. Os principais propósitos para o terceiro ano do Ensino Fundamental eram: a alfabetização e a consolidação da fala buscando expandir o vocabulário e procurando incentivar o diálogo através dos professores e das atividades.

As intervenções utilizadas ao longo dos trimestres foram de suma importância para analisar pontos significativos no processo de aprendizagem deste aluno, entre elas a qualificação da brincadeira lúdica tanto na disciplina de teatro, através do faz de conta e a criação de cenários juntamente com os colegas de turma, como na polivalência, trazendo materiais interativos e brinquedos para a sala de aula; o faz de conta possibilitou um contato maior com os colegas e com as professoras além de trazer um maior repertório de diálogos para as situações criadas.

O brincar está sendo cada vez mais utilizado na educação construindo-se numa peça importantíssima nos domínios da inteligência, na evolução do pensamento e de todas as funções superiores, transformando-se num meio viável para a construção do conhecimento. (SANTOS, 1999, p. 115).

A escrita começou a ser trabalhada, alternando do alfabeto concreto, com peças separadas, para a régua de letras, e após o domínio da régua para o material de contorno das letras; em paralelo a este exercício de escrita estava a adaptação da configuração de mão para segurar o lápis que já vinha sendo trabalhado desde o ano anterior de forma sutil e a partir do terceiro ano pôde ser introduzido de fato, o aluno avançou da preensão palmar supinada para a preensão palmar de transição. Para além da escrita está o avanço no processo de leitura, através da observação e das práticas o estudante apresentou uma busca por qualquer configuração de texto que houvesse em objetos, embalagens, papéis, entre outros, mesmo sem realizar a leitura de fato de cada palavra, mas atento às letras e números presentes nos objetos que o rodeiam.

A partir de atividades realizadas em sala de aula e em atendimento, pode-se perceber que o processo de escrita do aluno caracterizava-se pela memorização da organização das letras nas palavras, ou seja, o entendimento de como tal palavra era escrita não se dava pela associação letra-som e sim pela memória de qual letra colocava-se após a outra. Segundo Sacks (2006, p. 251), “[...] não há duas pessoas com autismo que sejam iguais; sua forma precisa ou expressão é diferente em cada caso"; posteriormente a essa observação, o modo de trabalhar a alfabetização tomou um novo rumo e as atividades foram readaptadas a fim de explorar essa especificidade na aprendizagem e criar novas oportunidades para ele. O que antes era proposto como mapear o alfabeto relacionando cada letra com o seu som, passou a ser modificado incrementando os gostos do aluno (como o nome do cantor favorito, nome de personagem, entre outras palavras que faziam parte de sua vida e lhe gerava interesse) para trabalhar com a repetição visando a estimular a memória.

A educação física também foi uma ferramenta importante na aproximação com os colegas, através de simples atividades como passar a bola, fazer roda, e realizar práticas em grupo as relações sociais foram se tornando mais significativas; muitas vezes a participação nas atividades propostas em aula não funcionava da forma como esperada pelos professores por questões comportamentais, entretanto outras possibilidades puderam ser criadas nessas situações como chamar o nome do colega que iria realizar a tarefa, dar a ordem de início das atividades e observar os movimentos de cada um e suas reações.

No convívio com outras crianças aprende a dar e receber ordens, a esperar sua vez de brincar, a emprestar e tomar como empréstimo o seu brinquedo, a compartilhar momentos bons e ruins, a fazer amigos, a ter tolerância e respeito, enfim, a criança desenvolve a sociabilidade. (RIBEIRO, 2002, p. 56).

Um dos conteúdos contemplados pela turma ao longo do ano foi a geografia espacial, mais especificamente os conceitos de cidade, bairro, rua, etc. o Google Maps foi uma das ferramentas utilizadas nas aulas, permitindo que cada um localizasse seu endereço; essa atividade foi essencial para a integração com a turma, despertando um interesse do aluno ao percorrer seu endereço no site e analisando cada detalhe presente na configuração de uma rua, como as placas por exemplo. Ao realizar a observação do próprio endereço, o aluno se sentiu pertencente àquele espaço e pôde através da fala caracterizar os lugares que conhecia, o 
mercado foi caracterizado pelo local onde compra-se comidas e usa-se carrinho de compras, a casa da mãe, onde dormia, tomava café e saía para a escola, além de apontar lugares aparentemente conhecidos; através da observação das placas foi possível trabalhar com a escrita, como por exemplo a palavra "PARE" que já é escrita sem apoio da professora, somente com o alfabeto móvel. Posteriormente a isso, saímos do digital e levamos a proposta de reconhecimento do espaço para a brincadeira com cenários e personagens, a fim de também contemplar outra atividade que estava sendo realizada paralelamente pela área das línguas estrangeiras: a rotina diária; através dos cenários criados pela turma com materiais descartáveis recriamos o dia a dia do aluno em casa, na escola e trazendo também o cenário do mercado para a brincadeira.

\section{Conclusões}

Vivenciar os processos de aprendizagem de um aluno com TEA significa estar disposto diariamente a mudar as práticas pedagógicas, as ferramentas de intervenção e até mesmo utilizar-se de estratégias diferenciadas para elaborar recursos que facilitem a aprendizagem; antes de tudo é necessário colocar em prática a transversalidade da educação especial, assegurando uma educação de qualidade e o acesso à escola de ensino regular para todos e fazendo da educação inclusiva uma modalidade acessível da educação infantil à educação superior. É na formação de professores e nos múltiplos espaços da universidade que se combate a exclusão e se constrói uma sociedade baseada nas políticas de inclusão social através do ensino, da pesquisa e da extensão.

Ninguém começa a ser educador numa terça-feira às quatro da tarde. Ninguém nasce educador ou marcado para ser educador. A gente se faz educador, a gente se forma, como educador, permanentemente na prática e na reflexão sobre a prática. (FREIRE, 1991, p. 58).

As práticas pedagógicas são fundamentais na trajetória de professores em formação, o olhar para a docência se faz mais respeitoso e a experiência torna-se um fator essencial para a criação de novos currículos capazes de contemplar a pluralidade social, as necessidades educativas especiais e a educação inclusiva. Fazer do ensino público uma ferramenta potente que prioriza o aluno e atende suas necessidades significa construir docentes experientes e qualificados, possibilitando que relatos como este sejam cada vez mais recorrentes e os processos de aprendizagem se tornem mais acessíveis e adaptados.

\section{Referências}

ALVES, Rubens. Ensinar, cantar, aprender. Campinas: Papirus, 2008. Inclui um CD com músicas de Marcílio Menezes. AMERICAN PSYCHIATRIC ASSOCIATION. DSM-5: manual diagnóstico e estatístico de transtornos mentais. Porto Alegre: Artmed, 2014.

RIO GRANDE DO SUL. Lei no 15.322 , de 25 de setembro de 2019. Institui a Política de Atendimento Integrado à Pessoa com Transtornos do Espectro Autista no Estado do Rio Grande do Sul. Diário Oficial [do] Estado do Rio Grande do Sul, Porto Alegre, 25 set. 2019.

FREIRE, Paulo. A educação na cidade. São Paulo: Cortez, 1991.

RIBEIRO, Paula Simon. Jogos e brinquedos tradicionais. In: SANTOS, Santa Marli Pires dos. Brinquedoteca: o lúdico em diferentes contextos. 7. ed. Petrópolis: Vozes, 2002. p. 55-61.

SACKS, Oliver. Um antropólogo em Marte. São Paulo: Companhia das Letras, 2006.

SANTOS, Santa Marli Pires dos. Brinquedo e infância. Petrópolis: Vozes, 1999.

SILVA, Ana; ALVES, Cristina; SOUZA, Luciane de; PAULINO, Marcos; SANTOS, Mônica. Paulo Freire - pedagogia da diversidade? In: COLÓQUIO INTERNACIONAL PAULO FREIRE, 5., 2005, Recife. Atas [...]. Recife: UFPE, 2005. 
Os processos de aprendizagem e o Transtorno do Espectro do Autismo (TEA)...

SILVA, Karla; BINS, Katiuscha (org.). Tessituras do fazer pedagógico junto a alunos com Transtorno do Espectro Autista: o cotidiano numa escola especial da Prefeitura de Porto Alegre. Porto Alegre: Secretaria Municipal de Educação, 2016.

VALLE, Jan; CONNOR, David. Ressignificando a deficiência: da abordagem social às práticas inclusivas nas escolas. Porto Alegre: AMGH, 2014.

Data de submissão: 06/12/2019

Data de aceite: 02/07/2020 